\title{
A Development of Ceramics Cylinder Type Sulfuric Acid Decomposer for Thermo-Chemical Iodine-Sulfur Process Pilot Plant
}

\author{
Isao MINATSUKI ${ }^{* *}$, Hiroshi FUKUI ${ }^{* * *}$ and Kazuo ISHINO ${ }^{* * * *}$ \\ **Nuclear Systems Engineering Department \\ Nuclear Energy Systems Engineering Center \\ Nuclear Energy Systems Headquarters \\ Mitsubishi Heavy Industries, Ltd. \\ 16-5, Konan 2-chome, Minato-ku, Tokyo 108-8215 Japan \\ ${ }^{* * *}$ Quantum-Mechanical System Designing Group \\ Nuclear Fuel \& Back-End Systems Designing Department \\ Mitsubishi Heavy Industries, Ltd. \\ 1-1, Wadasaki-cho 1-chome, Hyogo-ku, Kobe 652-8585 \\ ****Market Development Group \\ Fine Ceramics Division \\ Pacific Rundum Co., Ltd. \\ 1-Iwase Akadamachi Toyama 931-8555 Japan
}

\begin{abstract}
The hydrogen production method applying thermo-chemical Iodine-Sulfur process (IS process) which uses a nuclear high temperature gas cooled reactor is world widely greatly concerned from the view point of a combination as a clean method, free carbon dioxide in essence. In this process, it is essential a using ceramic material, especially $\mathrm{SiC}$ because a operation condition of this process is very corrosive due to a sulfuric acid atmosphere with high temperature and high pressure. In the IS process, a sulfuric acid decomposer is the key component which performs evaporating of sulfuric acid from liquid to gas and disassembling to $\mathrm{SO}_{2}$ gas. $\mathrm{SiC}$ was selected as ceramic material to apply for the sulfuric acid decomposer and a new type of binding material was also developed for SiC junction. This technology is expected to wide application not only for a sulfuric acid decomposer but also for various type components in this process. Process parameters were provided as design condition for the decomposer. The configuration of the sulfuric acid decomposer was studied, and a cylindrical tubes assembling type was selected. The advantage of this type is applicable for various type of components in the IS process due to manufacturing with using only simple shape part. A sulfuric acid decomposer was divided into two regions of the liquid and the gaseous phase of sulfuric acid. The thermal structural integrity analysis was studied for the liquid phase part. From the result of this analysis, it was investigated that the stress was below the strength of the breakdown probability $1 / 100,000$ at any position, base material or junction part. The prototype model was manufactured, which was a ceramic portion in the liquid phase part, comparatively complicated configuration,
\end{abstract}


of a sulfuric acid decomposer. The size of model was about $1.9 \mathrm{~m}$ in height, $1.0 \mathrm{~m}$ in width. Thirty-six cylinders including inlet and outlet nozzles were combined and each part article was joined using the new binder (slurry binder) and calcinated. Final polishing of the flange faces established in the entrance nozzles was also satisfactory. Many parts were joinable using new technology (new binder). For this reason, new technology is applicable to manufacture of not only a sulfuric acid decomposer but the instruments in the IS process, or other chemical processes.

Key words: Hydrogen, IS Process, HTGR, Ceramics, SiC, Heat-Exchanger, Sulfuric-Acid Decomposer

\section{Introduction}

Hydrogen energy system has attracted much interest these days mainly because of the recent progress of the promising hydrogen utilization technology, fuel cells, and of the growing interest on the cleaner energy due to the increasing concern on the environmental issues such as the global warming caused by the greenhouse effect. To meet the anticipated future huge demand, development of effective routes for hydrogen production is an urgent issue. As for the primary energy, nuclear energy is a promising candidate, which stably supplies large amount of energy with no carbon dioxide emission. High Temperature Gas-Cooled Reactor (HTGR) that features high level of inherent safety and ability to supply heat of very high temperature up to $950^{\circ} \mathrm{C}$ is quite suitable for hydrogen production [1]. Thermo-chemical water-splitting cycle is a method to make an effective use of the high temperature nuclear heat for hydrogen production. It works like a chemical engine to produce hydrogen from water by combining high temperature endothermic chemical reactions and low temperature exothermic chemical reactions [2]. IS process consists of three steps as follows:

$$
\begin{array}{lc}
\mathrm{I}_{2}+\mathrm{SO}_{2}+2 \mathrm{H}_{2} \mathrm{O}=2 \mathrm{HI}+\mathrm{H}_{2} \mathrm{SO}_{4} & 100^{\circ} \mathrm{C} \\
\mathrm{H}_{2} \mathrm{SO}_{4}=\mathrm{SO}_{2}+\mathrm{H}_{2} \mathrm{O}+0.5 \mathrm{O}_{2} & 850^{\circ} \mathrm{C} \\
2 \mathrm{HI}=\mathrm{I}_{2}+\mathrm{H}_{2} & 450^{\circ} \mathrm{C}
\end{array}
$$

In IS process, water as raw material is reacted with iodine $\left(\mathrm{I}_{2}\right)$ and sulfur dioxide $\left(\mathrm{SO}_{2}\right)$ to produce hydrogen iodide (HI) and sulfuric acid $\left(\mathrm{H}_{2} \mathrm{SO}_{4}\right)$ in so-called the Bunsen reaction. The products are then decomposed endothermically to produce hydrogen $\left(\mathrm{H}_{2}\right)$ and oxygen $\left(\mathrm{O}_{2}\right)$, respectively. Iodine and sulfur dioxide produced in the decomposition reactions can be used again as the reactants in the Bunsen reaction.

The continuous hydrogen production operation for one week was demonstrated in Japan Atomic Energy Agency (JAEA) using a bench-scale test apparatus made of glass [3, 4]. The hydrogen production rate was about $30 \mathrm{NL} / \mathrm{hr}$ [4]. Based on the test results and know-how obtained through the bench-scale tests, a pilot test plant which has a hydrogen production performance of $30 \mathrm{Nm}^{3} / \mathrm{hr}$ is being conceptually designed as the next step of IS process development aiming to realize a future nuclear hydrogen production $[4,5]$. Figure 1 shows a candidate of flow diagram for the pilot test plant [6]. The pilot test plant is to be fabricated with industrial materials such as high silicon steel, glass coated steel, SiC ceramics etc., and will be operated under the high pressure up to $2 \mathrm{MPa}$. A helium (He) gas loop with a $400 \mathrm{~kW}$ electric heater is used instead of HTGR. 
One of the key components of the IS process plant is a sulfuric acid decomposer, which decomposes $\mathrm{H}_{2} \mathrm{SO}_{4}$ into $\mathrm{SO}_{3}$ and $\mathrm{H}_{2} \mathrm{O}$ under high temperature conditions up to $527^{\circ} \mathrm{C}$. Since the working condition is strongly corrosive, the sulfuric acid decomposer should be fabricated with a corrosion-resistant material. Only ceramics is expected to keep more corrosion-resistant performance under the boiling conditions of $\mathrm{H}_{2} \mathrm{SO}_{4}$. A.Broggi et al. demonstrated the ability of the ceramics type sulfuric acid decomposer attached to the CRISTINA process; A demonstration facility for thermal decomposition of $\mathrm{H}_{2} \mathrm{SO}_{4}$ into $\mathrm{SO}_{2}$ and $\mathrm{O}_{2}$ [7]. They used refractory bricks composed of $\mathrm{SiO}_{2}$ and $\mathrm{Al}_{2} \mathrm{O}_{3}$ for the internal construction material. Recently $\mathrm{SiC}$ ceramics is considered as a adequate material to sulfuric acid decomposition condition.

Mitsubishi Heavy Industries, LTD.(MHI) has a wide array of experiences in the engineering, procurement, and construction (EPC) of various types of chemical plants, for example, sulfuric acid plant, nitric acid plant, hydrogen plant, process automation, process analysis and control technology, and various others. Taking advantage of these experiences, MHI has carried out energetically R\&D on thermo-chemical hydrogen production by using the IS process [6]. As a part of R\&D, the sulfuric acid decomposer was developed by MHI. A concept of the $\mathrm{SiC}$ ceramics cylinder type sulfuric acid decomposer for the pilot test plant was described in this paper. Preliminary analyses of temperature distributions and of thermal stress in the sulfuric acid decomposer were carried out. A manufacturing test for a sulfuric acid decomposer model of a cylinder type was examined.

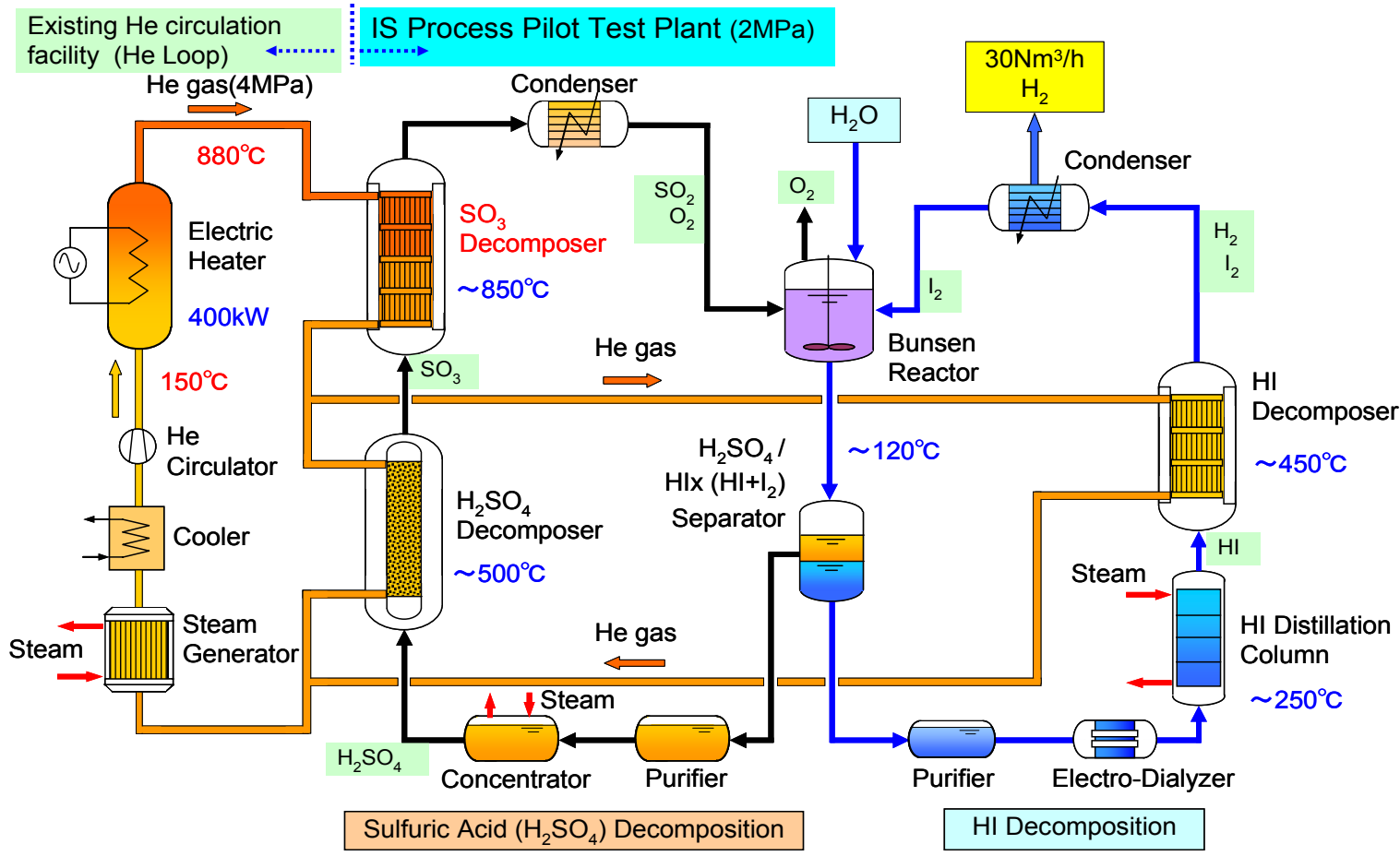

Fig.1 Schematic flow diagram of the IS process pilot test plant

\section{Specification of sulfuric acid decomposer}

\subsection{Design Conditions}

It is treated a liquid phase of the sulfuric acid with the sulfuric acid decomposer. A comparatively large heat transfer coefficient can be obtained without depending on the configuration. It is comparatively simple to manufacture a cylinder type sulfuric acid 
decomposer. Moreover, in the case of a cylinder type heat exchanger, the function of the condenser (Fig.1) may be incorporable into a sulfuric acid decomposer. This improves the heat efficiency in the IS process. According to these reasons, MHI developed the cylinder type sulfuric acid decomposer made of SiC.

Tables 1 and 2 show the design conditions for the sulfuric acid decomposer in the pilot test plant based on the conditions in literature [8]. SiC ceramics, which is a high thermal resistant material, is presently the most promising material for the sulfuric acid decomposer to meet following requests:

- High thermal conductivity necessary to transfer heat effectively by high temperature He gas ( $\left.\max 688^{\circ} \mathrm{C}\right)$,

- Anti-corrosiveness against the process liquid, or gas such as the high temperature $\mathrm{H}_{2} \mathrm{SO}_{4}$,

- High mechanical strength to withstand the static pressure difference between He gas and process liquid, or gas.

Table 1 Design conditions of the sulfuric acid decomposer in pilot test plant

\begin{tabular}{|l|c|}
\hline \multicolumn{1}{|c|}{ Item } & $\begin{array}{c}\text { Conditions for hydrogen } \\
\text { production } 30 \mathrm{~N} \mathrm{~m}^{3} / \mathrm{h}\end{array}$ \\
\hline Process fluid pressure & $2.0(\mathrm{MPaG})$ \\
\hline $\begin{array}{l}\text { Process fluid } \\
\text { temperature (inlet/outlet) }\end{array}$ & $391 / 527\left({ }^{0} \mathrm{C}\right)$ \\
\hline He pressure (inlet) & $4.0(\mathrm{MPaG})$ \\
\hline He flow rate & $100(\mathrm{~g} / \mathrm{s})$ \\
\hline He temperature (inlet) & $688\left({ }^{0} \mathrm{C}\right)$ \\
\hline Heat exchange & $127(\mathrm{~kW})$ \\
\hline
\end{tabular}

Table 2 Flow conditions of process fluid

\begin{tabular}{|c|c|c|}
\hline \multirow{2}{*}{ Process gas } & \multicolumn{2}{|c|}{ Mol flow } \\
\cline { 2 - 3 } & $\begin{array}{c}\text { Inlet } \\
\left(391^{0} \mathrm{C}\right)\end{array}$ & $\begin{array}{c}\text { Outlet } \\
\left(527^{0} \mathrm{C}\right)\end{array}$ \\
\hline $\mathrm{H}_{2} \mathrm{O}$ & 0.459 & 0.931 \\
\hline $\mathrm{H}_{2} \mathrm{SO}_{4}$ & 0.758 & 0.286 \\
\hline $\mathrm{SO}_{3}$ & 0 & 0.441 \\
\hline $\mathrm{SO}_{2}$ & 0 & 0.0316 \\
\hline $\mathrm{O}_{2}$ & 0 & 0.0158 \\
\hline \hline Total & 1.217 & 1.71 \\
\hline
\end{tabular}

\subsection{Concept of a sulfuric acid decomposer}

In the design condition, it was calculated that sulfuric acid was boiled at about $485^{\circ} \mathrm{C}$. In a sulfuric acid decomposer, the sulfuric acid of a liquid phase is heated and boiled to $485^{\circ} \mathrm{C}$, and that of a gas phase is super-heated to $527^{\circ} \mathrm{C}$. The heat-transfer forms differ in the evaporation part and gas phase super-heating part. Moreover, the points on a design taking into consideration also differ. For this reason, it was considered as the constitution of dividing a sulfuric acid decomposer into two regions. The configuration which was adapted for each, was selected.

Figures 2 and 3 show the concept of the evaporation part and gas phase super-heating part respectively in a sulfuric acid decomposer for the pilot test plant.

The evaporation part is a heat exchanger by the cross flow of helium gas (heating source), which has the parallel arrangement of sulfuric acid passes. (Fig.2) The sulfuric acid 
which flows the inside of cylindrical toward a top from the bottom is heated and decomposed by the high temperature helium gas which flows the surface of the tubes. A metal outer cover is prepared in the exterior of a heat exchanger, since the pass of helium is constituted. Helium flows in a direction perpendicular to the cylinder to direct toward the lower part from the upper part. By adoption of the cross flow of helium, the temperature distribution of the heat exchanger, ceramics cylinder, becomes uniform. As a result, the thermal stress of the heat exchanger is expected to reduce.

The gas phase super-heating part is a double-cylinder type heat exchanger by the counter flow. (Fig.3)

The evaporation part is installed in a pressure vessel lined internally with thermal insulator. Three units of heat exchangers which are made from ceramics cylinder are assembled into the pressure vessel (Fig.4).

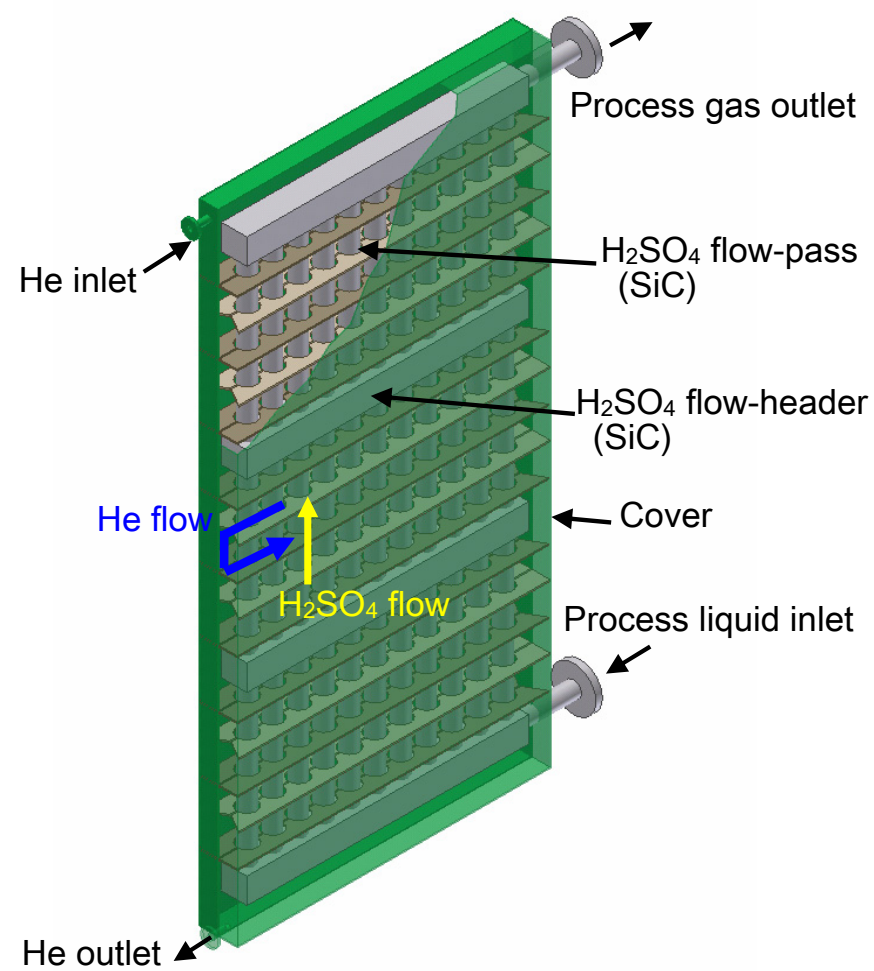

Fig.2 Concept of evaporation part of $\mathrm{H}_{2} \mathrm{SO}_{4}$ decomposer

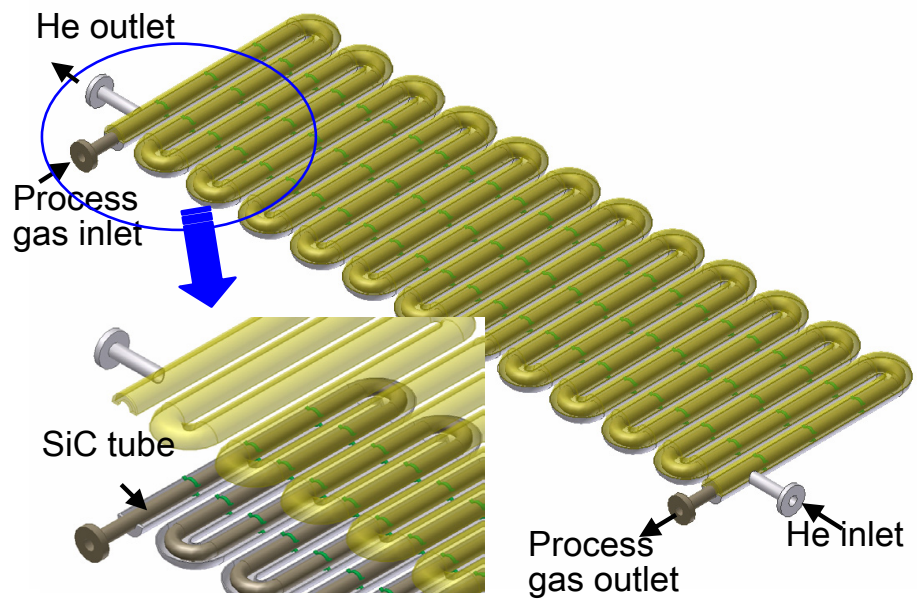

Fig.3 Concept of gas phase super-heating part of $\mathrm{H}_{2} \mathrm{SO}_{4}$ decomposer 


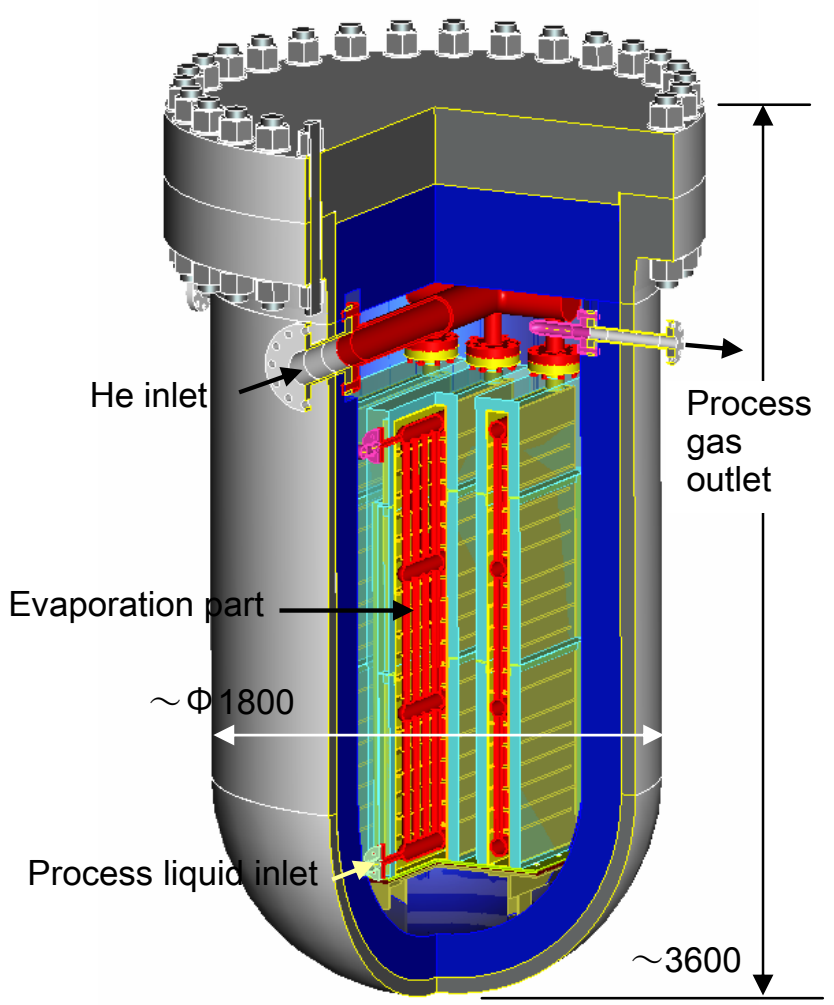

Fig.4 Concept of evaporation part in vessel

The main specification of the evaporation part and gas phase super-heating part is summarized in Table 3.

Table 3 Main specification of sulfuric acid decomposer

\begin{tabular}{|c|c|c|}
\hline Item & Evaporation part & Super-heating part \\
\hline $\begin{array}{c}\text { Number of units for } \\
\text { pilot plant }\end{array}$ & 3 & 3 \\
\hline $\begin{array}{c}\text { Number of parallel } \\
\text { flow tubes }\end{array}$ & 10 & 1 \\
\hline $\begin{array}{c}\mathrm{H}_{2} \mathrm{SO}_{4} \text { temperature } \\
(\mathrm{I} / \mathrm{O})\end{array}$ & $391 / 485\left({ }^{\circ} \mathrm{C}\right)$ & $485 / 527\left({ }^{0} \mathrm{C}\right)$ \\
\hline He temperature (inlet) & $666\left({ }^{0} \mathrm{C}\right)$ & $688\left({ }^{0} \mathrm{C}\right)$ \\
\hline Heat exchange & $38(\mathrm{~kW})$ & $4(\mathrm{~kW})$ \\
\hline Heat transfer area & $2.1\left(\mathrm{~m}^{2}\right)$ & $1.8\left(\mathrm{~m}^{2}\right)$ \\
\hline
\end{tabular}

Necessary heat transfer area for each part was decided on the basis of conservative heat transfer evaluation which was shown in the following chapter. The basic dimensions of heat exchangers were determined using these values. Size and total number of $\mathrm{SiC}$ cylinders were defined as follows from the viewpoints of the present manufacturing facility on SiC ceramics.

Evaporation part

- Height : $1900 \mathrm{~mm}$ 
- Width : $1000 \mathrm{~mm}$

- Thickness : $100 \mathrm{~mm}$

- Diameter of heat transfer pipe : $50 \mathrm{~mm}$

Super-heating part

- Length : $2200 \mathrm{~mm}$

- Width : $700 \mathrm{~mm}$

- Thickness : $100 \mathrm{~mm}$

- Diameter of heat transfer pipe : $50 \mathrm{~mm}$

The other dimension of a sulfuric acid decomposer (evaporation part) is shown in Figure 4.

\section{Temperature-distribution and Thermal Stress Analyses}

\subsection{Temperature Distribution Analyses}

\subsubsection{Analytical Conditions}

Compared with the gas phase heating part, the evaporation part is structured little more complicated. Therefore, temperature distribution analysis and thermal structure analysis were conducted for the evaporating part.

In the sulfuric acid decomposer, sulfuric acid as the process fluid goes up the inside of ceramic heat transfer tube, and evaporates after it is heated by helium flowing perpendicularly to the outside of the heat transfer tube. Sulfuric acid is supplied in the sub-cool condition, and stirred in the heat transfer tube by natural circulation and boiling. Therefore, heat transfer shall be evaluated by pool boiling heat transfer. Since there is no common information available in the boiling heat transfer of sulfuric acid, the following simplified formula for water pool boiling by Stephan-Abdelsalam was used [9].

$$
\begin{aligned}
N u=c_{1} & \times q^{0.673} \\
N u & : \text { Nusselt number [-] } \\
c_{1} & : \text { Coefficient specified by fluid pressure [-] } \\
q & : \text { Heat flux }\left[\mathrm{W} / \mathrm{m}^{2}\right]
\end{aligned}
$$

Heat transfer in the helium side is by the flow perpendicular to cylinder, and therefore, the formula of cylinder's turbulent flow using average Nusselt number by Zukauskas was selected [10].

$$
\begin{aligned}
N u_{m}= & C_{1} \operatorname{Re}^{n} \operatorname{Pr}^{0.37}\left(\frac{\operatorname{Pr}}{\operatorname{Pr}_{w}}\right)^{0.25} \\
N u_{m} & : \text { Average Nusselt number [-] } \\
C_{1} & : \text { Coefficient determined by Reynolds number } \\
\operatorname{Re} & : \text { Reynolds number [-] } \\
\mathrm{n} & : \text { Coefficient determined by Reynolds number [-] } \\
\operatorname{Pr} & : \text { Prandtl number [-] } \\
\operatorname{Pr}_{w} & : \text { Prandtl number at wall [-] }
\end{aligned}
$$

Reynolds number in the helium side was approximately 4100 .

The heat transfer condition of sulfuric acid for temperature distribution analysis is as follows. The heat from He transfers to sulfuric acid in liquid and vapor phase and an amount of heat in sulfuric acid are calculated with value of transferred heat and decomposition heat in addition. 


\subsubsection{Result}

Figure 5 shows the result of calculating the temperature distribution in the ceramic part of the sulfuric acid decomposer shown in Figure 2. Number of returns is larger for the helium flowing that flowed vertically along heat transfer tube. Therefore, the temperature distribution among flow paths is very small. Temperature of the heat transfer tube becomes higher smoothly from the lower (inlet) to upper (outlet).
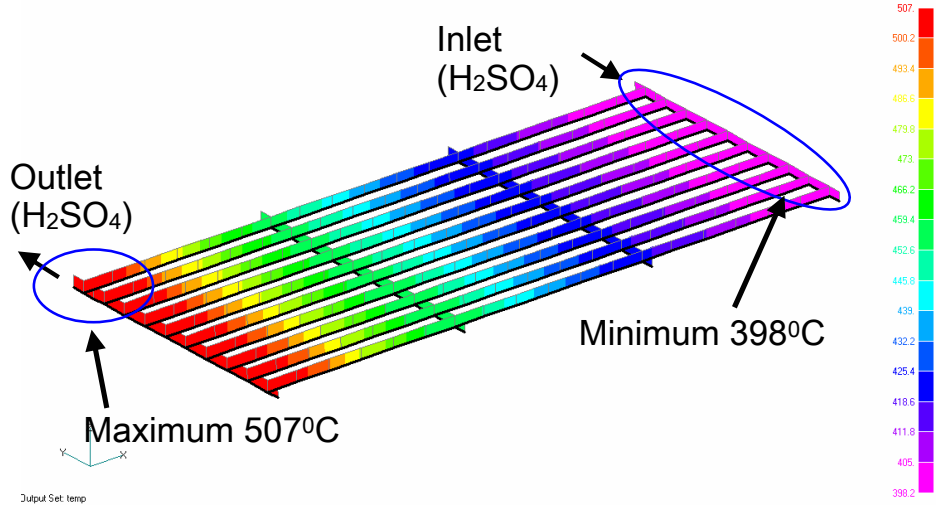

Fig.5 Temperature distribution of sulfuric acid decomposer

\subsection{Thermal Stress Analyses}

\subsubsection{Analytical Conditions 1}

Thermal stress analyses were conducted by the following procedure.

a. Modeling the whole system of ceramic heat transfer tube by beam elements (whole system model).

b. Analyzing and evaluating stresses by giving the temperature distribution obtained as above to the whole system.

c. Configuring three-dimensional model (3D model) of relevant part by focusing on the position of highest stress from the analysis result of the whole system model.

d. Carrying out detailed analysis of temperature distribution for 3D model by using the fluid temperature and the heat transfer coefficient obtained in the previous chapter

e. Evaluating the obtained stress by analyzing the thermal stresses by the above temperature distribution.

Computer code used in the analysis of whole system model was NASTRAN, version 2004 [11]. Restraint conditions for the whole system model were fixed at one position, and freed elsewhere.

The material properties of $\mathrm{SiC}$ were determined using actual measurement values, which were observed in experiments of temperature changing.

Physical properties of $\mathrm{SiC}$ used in the calculation were follows (at $500^{\circ} \mathrm{C}$ ).

Young's modulus (E): 363 [GPa]

Poisson's ratio $(v): 0.174[-]$

Thermal conductivity $(\lambda): 76[\mathrm{~W} / \mathrm{m} \cdot \mathrm{K}]$

Thermal expansion coefficient $(\alpha): 3.6 \times 10^{-6}\left[\mathrm{~K}^{-1}\right]$

The whole ceramic heat exchanger part is installed with hanging and supported from the upper part of a header. Other parts are supported and the contact parts between structure part and support parts have flexibility by sliding of the contact parts. Although there is a possibility that junction of a nozzle flange part might receive the force from the structure 
part, however, since the boundary condition between nozzles and connecting pipes could not be determined due to instillation condition of the heat exchanger were not clarified, this part were not selected for the structural integrity analysis in this study .

The restriction condition of analysis of the ceramic heat exchanger is basically designed as same condition between during operation.

\subsubsection{Result 1}

Figure 6 shows the result of analyzing the whole system model. Maximum stress occurred at the outlet portion of sulfuric acid decomposer, and its value was 6.5 MPa. The strength of the breakdown probability 1/100,000 (limit value) of ceramic SiC used in the sulfuric acid decomposer is $80.5 \mathrm{MPa}$. The maximum stress was smaller than the limit value. The limit value was defined from the results of a bending destruction test of SiC piece. These are the probabilistic values, which are calculated supposing with Weibull distribution $F=1-\exp \left[-\left(\frac{x}{a}\right)^{m}\right]$ and $1 / 10^{5}$ as a destructive probability.

Here $\quad m=8.5 \quad a=315.9$.

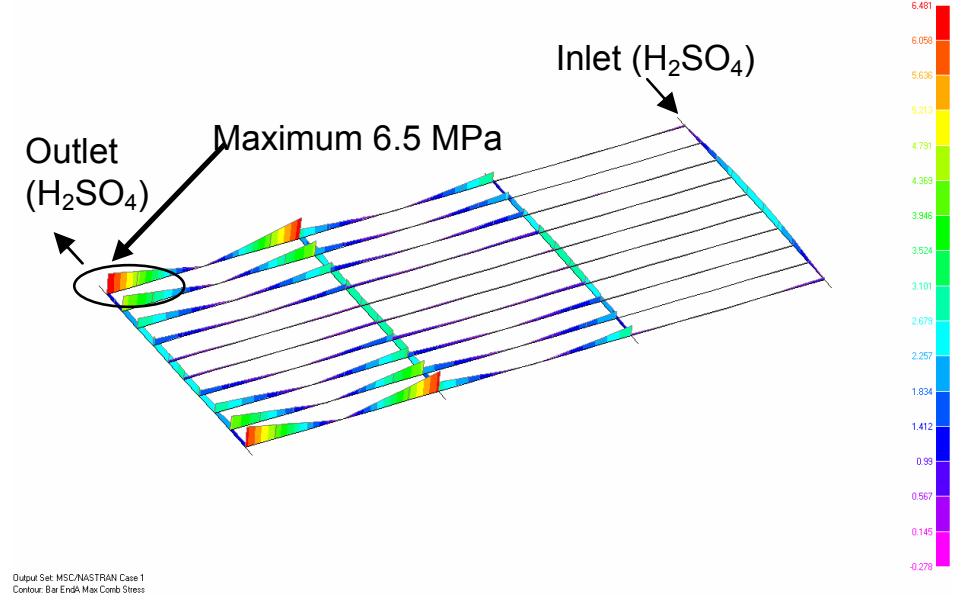

Fig.6 Stress distribution for the whole system model

\subsubsection{Analytical Conditions 2}

The outlet portion (Figs.6 and 7) of sulfuric acid decomposer, where max stress has occurred according to the analysis result of whole system model, was modeled three-dimensionally. The stress at this part was calculated. Computer code used for the 3D model analysis was ANSYS version 10 [12].

Figure 7 shows the analytical model. For this model, detailed analysis of temperature distribution was conducted by using the fluid temperature and the heat transfer coefficient obtained in the previous chapter.

Figure 8 shows the result of temperature distribution. By using this temperature distribution, thermal stress analysis was carried on. Fluid pressures, and moments obtained from the whole system model were given as boundary conditions. The calculation analysis was performed assuming that, as for the helium temperature of the outside surface was constant and these on inner surface are calculated considering a boiling behavior of sulfuric acid. 


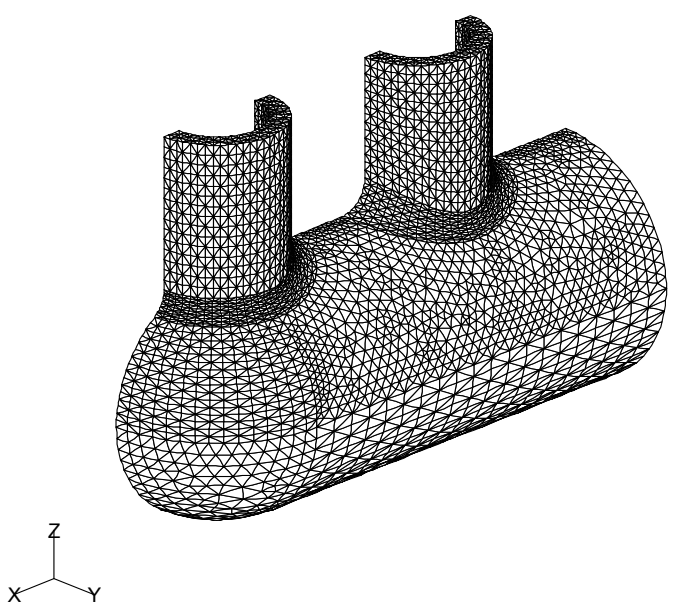

Fig.7 Analytical model for the detailed temperature distribution and thermal stress analysis (3D model)

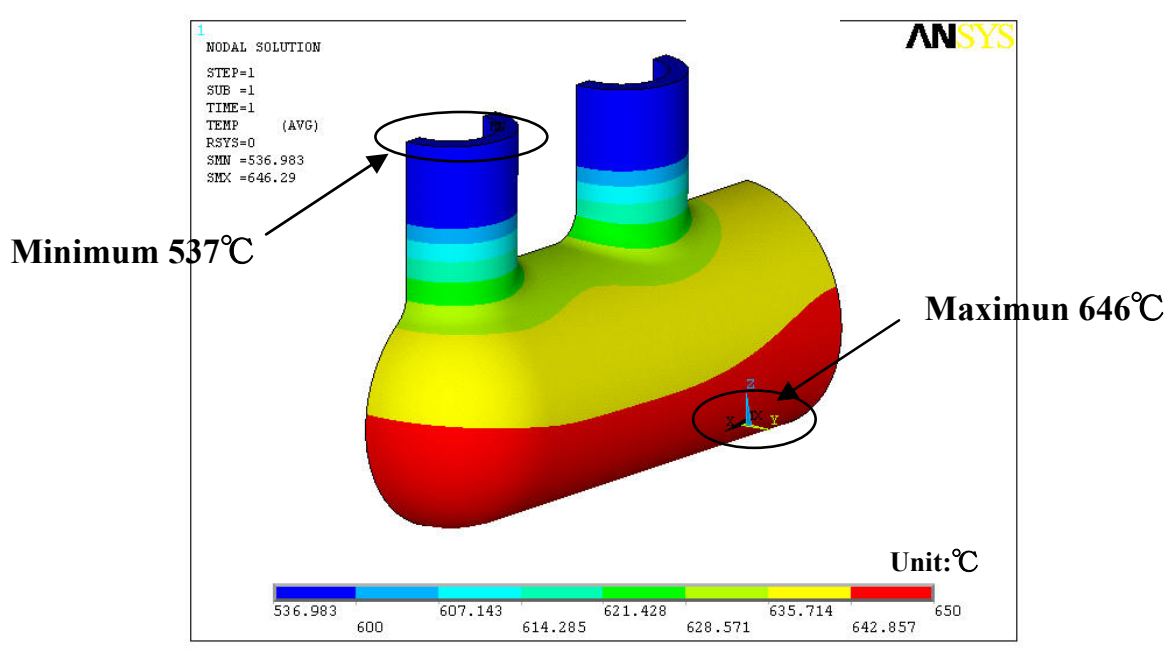

Fig.8 Temperature distribution around the outlet of the process flow

\subsubsection{Result 2}

Table 4 shows the result of thermal stress analysis. Maximum stress occurred in the case of losing pressure in the helium side. Contour of stress in such a case is shown in Figure 9. At any part and any case, stresses were less than the limit values.

The methods for thermal analysis and thermal stress analysis for sulfuric acid decomposer were suggested in this chapter. 

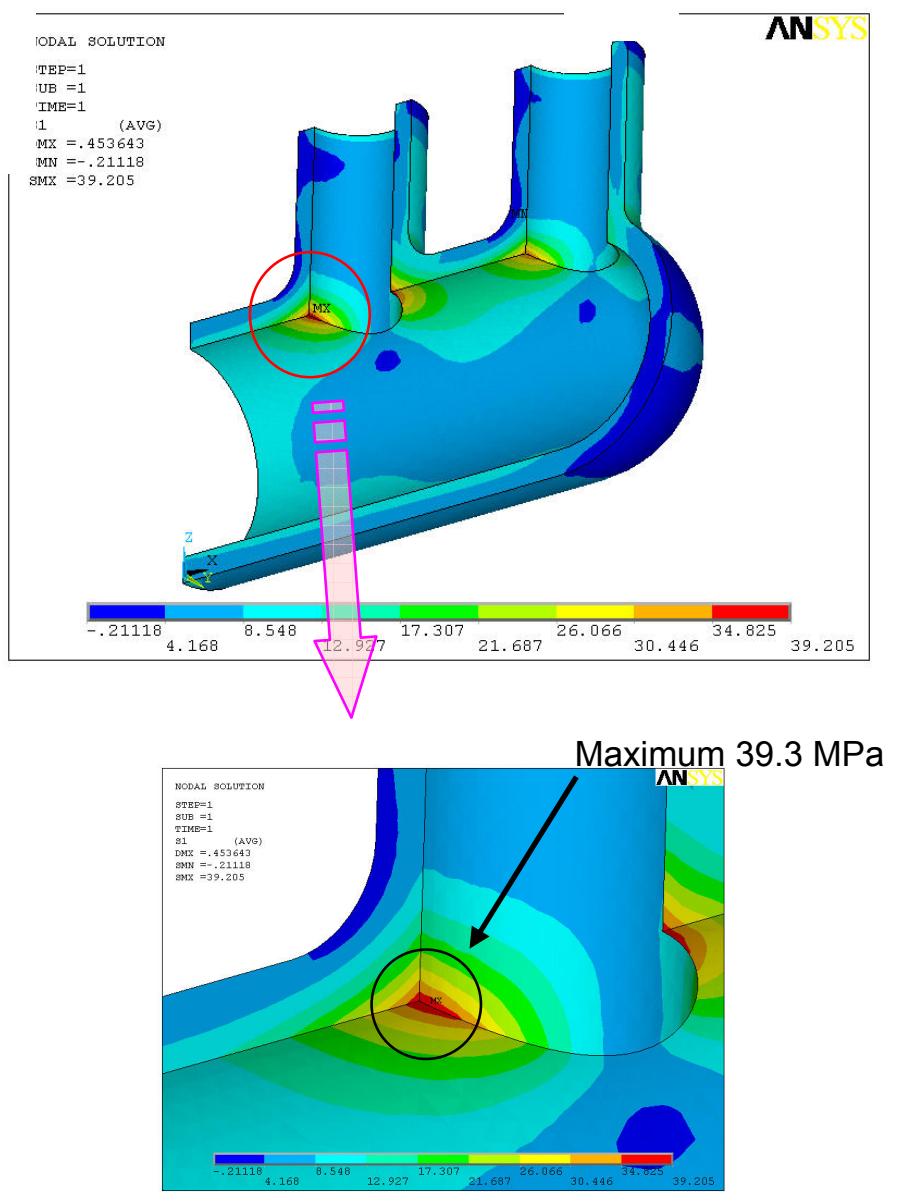

Fig.9 Stress distribution around the outlet of the process flow

Table 4 Result of thermal stress analyses

\begin{tabular}{|c|l|l|r|r|}
\hline No & & Occurs at & $\begin{array}{c}\text { Max stress } \\
(\mathrm{MPa})\end{array}$ & $\begin{array}{c}\text { Limit value } \\
(\mathrm{MPa})\end{array}$ \\
\hline 1 & $\begin{array}{l}\text { Normal } \\
\text { operation }\end{array}$ & Base material & 11.8 & 80.5 \\
\cline { 3 - 5 } & Joint & 5.9 & 34 \\
\hline \multirow{2}{*}{$\begin{array}{l}\text { Pressure loss } \\
\text { in helium }\end{array}$} & Base material & 39.3 & 80.5 \\
\cline { 3 - 5 } & $\begin{array}{l}\text { Pressure loss } \\
\text { in sulfuric acid }\end{array}$ & Joint & 27.4 & 34 \\
\cline { 3 - 5 } & Base material & 9.7 & 80.5 \\
\hline
\end{tabular}

\section{Manufacturing Examination}

To examine for the following items in manufacturing process, a prototype model of heat exchanger for the sulfuric acid decomposer has been manufactured.

- Accuracy of connecting many pipes.

- Manufacturing verification including the calcinating of large-scale ceramics component.

- Manufacturing verification of connecting flange and polishing flange surface.

To investigate the above items, the prototype model has been manufactured in the same size as the heat exchanger planned for the pilot test plant. Pipes were connected by using the connecting slurry developed by MHI. Figure 10 shows the photos of the prototype model. A 
manufacturing procedure to assemble by connecting many ceramic pipes develops the possibility to manufacture various types of equipments including a sulfuric acid decomposer by connecting parts of various shapes.

For this prototype heat exchanger, appearance inspection (crack, leakage) and dimensional inspection were conducted. It has been confirmed that prototype model of the heat exchanger can be produced as designed by the inspection.

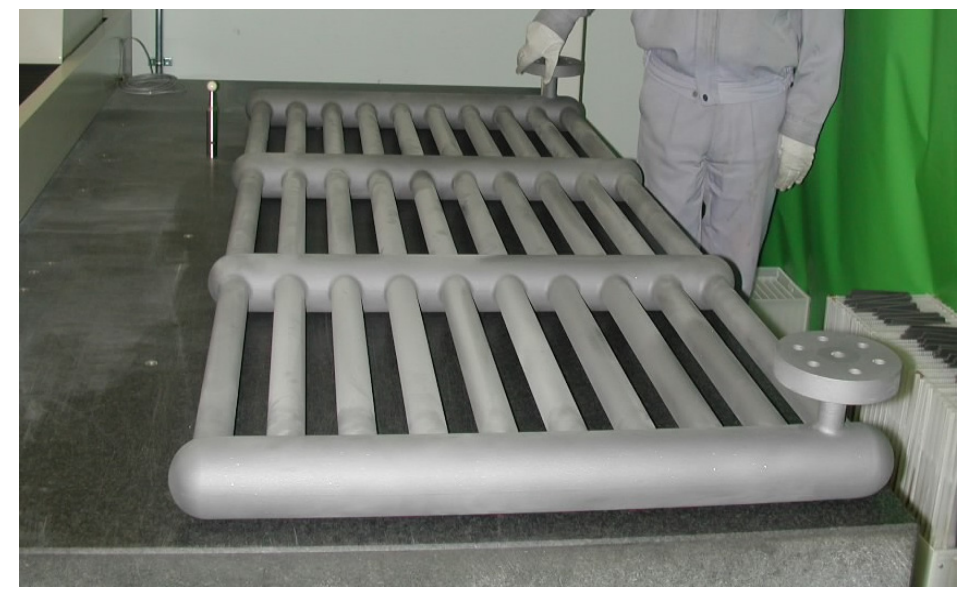

Fig. 10 Outer view of prototype model

\section{Conclusion}

A SiC ceramics cylinder type heat exchanger for a sulfuric acid decomposer in the IS process was conceptually designed. Pipe size and length, number of flow pass of heat exchanger were decided by the required heat exchange area and constructability.

Structural feasibility of the heat exchanger was analytically verified by the thermal analyses and thermal stress analyses.

Prototype manufacturing of full size heat exchanger was conducted based on the results of the analyses.

\section{References}

[1] Fujikawa, S., et al., 2004, "Achievement of Reactor-Outlet Coolant Temperature of $950^{\circ} \mathrm{C}$ in HTTR," J. Nucl. Sci. Technol., 41(12), pp. 1245-1254.

[2] Funk, J. E., and Reinstrom, R. M., 1966, "ENERGY REQUIREMENTS IN THE PRODUCTION OF HYDROGEN FROM WATER," I\&EC Process Design and Development, 5, pp. 336-342.

[3] Onuki, K., et al., 2004, "STUDY ON THERMOCHEMICAL IODINE-SLFUR CYCLE AT JAERI," ICONE12-49364, Proc. 12 ${ }^{\text {th }}$ International Conference on Nuclear Engineering, Arlington, Virginia, USA.

[4] Kubo, S., et al., 2004, "A pilot test plan of the thermochemical water-splitting iodine-sulfur process," Nucl. Eng. Des., 233, pp. 355-362.

[5] Terada, A., et al., 2005, "DEVELOPMENT PROGRAM OF HYDROGEN PRODUCTION BY THERMO-CHEMICAL WATER SPLITTING IS PROCESS," ICONE13-50183, Proc. $13^{\text {th }}$ International Conference on Nuclear Engineering, Beijing, China.

[6] Kanagawa, A., et al., 2005, "CONCEPTUAL DESIGN OF SO 3 DECOMPOSER FOR THERMO-CHEMICAL IODINE-SULFUR PROCESS PILOT PLANT," 
ICONE13-50451, Proc. $13^{\text {th }}$ International Conference on Nuclear Engineering, Beijing, China.

[7] Broggi, A., et al., 1980, "CRISTINA - A PROCESS FOR THE DECOMPOSITION OF SULPHURIC ACID," Proc. of $3^{\text {rd }}$ World Hydrogen Energy Conference, Tokyo, Japan, 4, pp. 1929-1937.

[8] Knoche, K. F., et al., 1984, "SECOND LAW AND COST ANALYSIS OF THE OXGEN GENERATION STEP OF THE GENERAL ATOMIC SULFUR-IODINE CYCLE," Proc. of $5^{\text {th }}$ World Hydrogen Energy Conference, Toronto, Canada, pp. 487-502.

[9] The Japan Society of Mechanical Engineers, 1986, JSME Data Book: Heat Transfer $4^{\text {th }}$ Edition, pp. 129.

[10] The Japan Society of Mechanical Engineers, 1986, JSME Data Book: Heat Transfer $4^{\text {th }}$ Edition, pp. 61.

[11] MSC.Software, 2003, "MSC.Nastran 2004 Release Guide," http://www.mscsoftware.co.jp/solutions/software/r 2004_nas.htm, (in Japanese).

[12] ANSYS. Inc, 2006, "ANSYS 10.0 Release New Features and Enhancements," http://www.ansys.com/products/newfeatures/default.asp. 